\title{
RESEARCH
}

Open Access

\section{Chloroquine efficacy studies confirm drug susceptibility of Plasmodium vivax in Chennai, India}

Sneh Shalini ${ }^{1 \dagger}$, Saumyadripta Chaudhuri ${ }^{1 \dagger}$, Patrick L Sutton ${ }^{2+}$, Neelima Mishra ${ }^{1}$, Nalini Srivastava ${ }^{3}$, Joseph K David ${ }^{4}$, K John Ravindran ${ }^{5}$, Jane M Carlton ${ }^{2}$ and Alex Eapen ${ }^{5^{*}}$

\begin{abstract}
Background: Assessing the Plasmodium vivax burden in India is complicated by the potential threat of an emerging chloroquine (CQ) resistant parasite population from neighbouring countries in Southeast Asia. Chennai, the capital of Tamil Nadu and an urban setting for P. vivax in southern India, was selected as a sentinel site for investigating CQ efficacy and sensitivity in vivax malaria.

Methods: CQ efficacy was evaluated with a 28-day in vivo therapeutic study, while CQ sensitivity was measured with an in vitro drug susceptibility assay. In both studies, isolates also underwent molecular genotyping to investigate correlations between parasite diversity and drug susceptibility to CQ. Molecular genotyping included sequencing a 604 base pair (bp) fragment of the P. vivax multidrug resistant gene-1 (Pvmdr1) for single nucleotide polymorphisms (SNPs) and also the amplification of eight microsatellite (MS) loci located across the genome on eight different chromosomes.

Results: In the 28-day in vivo study ( $N=125)$, all subjects were aparasitaemic by Day 14. Passive case surveillance continuing beyond Day 28 in 22 subjects exposed 17 recurrent infections, which ranged from 44 to 148 days post-enrollment. Pvmdr1 sequencing of these recurrent infections revealed that $93.3 \%$ had identical mutant haplotypes (958M/Y976/1076L) to their baseline Day 0 infection. MS genotyping further revealed that nine infection pairs were related with $\geq 75 \%$ haplotype similarity (same allele at six or more loci). To test the impact of this mutation on $C Q$ efficacy, an in vitro drug assay $(\mathrm{N}=68)$ was performed. No correlation between $I C_{50}$ values and the percentage of ring-stage parasites prior to culture was observed $\left(r_{\text {sadj: }}-0.00063, p=0.3307\right)$ and the distribution of alleles among the Pvmdri SNPs and MS haplotypes showed no significant associations with $\mathrm{IC}_{50}$ values.
\end{abstract}

Conclusions: Plasmodium vivax was found to be susceptible to CQ drug treatment in both the in vivo therapeutic drug study and the in vitro drug assay. Though the mutant 1076L of Pvmdr 1 was found in a majority of isolates tested, this single mutation did not associate with CQ resistance. MS haplotypes revealed strong heterogeneity in this population, indicating a low probability of reinfection with highly related haplotypes.

Keywords: Plasmodium vivax, Chloroquine, In vitro, In vivo, Genetic diversity, Chennai

\footnotetext{
* Correspondence: alexeapen@yahoo.com

${ }^{\dagger}$ Equal contributors

${ }^{5}$ National Institute of Malaria Research (Indian Council of Medical Research), National Institute of Epidemiology Campus, Second Main Road, Tamil Nadu Housing Board, Ayapakkam, Chennai 600 077, Tamil Nadu, India

Full list of author information is available at the end of the article
} 


\section{Background}

Assessing the Plasmodium vivax burden in India is complicated by the potential threat of an emerging chloroquine (CQ) resistant parasite population [1]. Plasmodium vivax resistance to CQ is rampant in some regions of Southeast Asia [2,3] and Western Pacific [4], while the emergence of CQ resistance within other regions of the world, including Central and South America [5-7], Southern Asia [8] and even the Indian Subcontinent [9-13] is less evident and represented in the literature mainly in the form of medical case reports. Similar to other countries (reviewed in [14]), CQ resistant Plasmodium falciparum emerged in India in the 1970s $[15,16]$. Decades of research have linked P. falciparum drug resistance with a variety of single nucleotide polymorphisms (SNPs) causing non-synonymous amino acid substitutions in the $P$. falciparum CQ resistance transporter gene $(P f c r t)$ [17] and copy number variation in the $P$. falciparum multidrug resistance gene 1 (Pfmdr1) [18]. However, mutations within Pfcrt appear to be more associated with CQ resistant phenotypes than copy number variation in Pfmdr1 [19-23]. Comparative studies between $P f c r t$ and the $P$. vivax ortholog, $P$. vivax candidate gene $10(P v c g 10)$, have not revealed similar functionality [24]. Yet, there is some evidence that specific SNPs causing non-synonymous amino acid substitutions within the $P$. vivax multidrug resistance protein 1 (Pvmdr1), the ortholog to $P f m d r 1$, may be associated with drug resistant phenotypes [25].

The Pvmdr1 gene has been characterized in several global genetic diversity studies in Thailand, Indonesia, Azerbaijan, Turkey, French Guyana, Brazil, Madagascar, Mauritania and most recently in China and India [26-36]. Over a dozen non-synonymous amino acid mutations have been reported [26-35]; of these, Y976F and F1076L are most frequently reported and correlated with CQ resistance $[27,34,35,37]$, although much work remains to irrefutably link these mutations with CQ resistance. In India, a recent study in Kolkata reported an absence of the Y976F mutation in $25 P$. vivax samples determined to be CQ sensitive taken from patients enrolled in a 28-day in vivo efficacy study [29]. Despite the fact that most drug resistant cases remain confined to specific regions in Southeast Asia and the Western Pacific, the impact of long-term CQ exposure on a parasite population is indisputable and has been studied extensively in P. falciparum. Recently, Mallick et al. [38] showed that a mutant (SVMNT) SNP haplotype of Pfcrt was found to predominate during 2002-2006 in regions with high $P$. vivax transmission, in conjunction with high CQ exposure during this time. Due to the fact that CQ remains the first line of defense against $P$. vivax, this highlights the epidemiological impact on the selection of drug resistant parasites in mixed species infections and the maintenance of genetic diversity in a population through inbreeding [38]. Though only a few cases of P. vivax CQ resistance have been observed in India [9-13], a selective sweep with a CQ resistant parasite population would have serious consequences for the control of vivax malaria [39-41].

Tamil Nadu, a state located in southern India, is one of several that are heavily burdened by $P$. vivax. The capital city, Chennai, has historically seen high $P$. vivax transmission. For these reasons, Chennai was selected as the sentinel site for investigating CQ sensitivity in $P$. vivax. In this study, the therapeutic efficacy of CQ was evaluated with an in vivo study, while CQ sensitivity was measured with an in vitro CQ drug assay. In both studies, isolates also underwent molecular genotyping to investigate if a correlation exists between parasite genetic diversity and drug susceptibility to CQ. Molecular genotyping included sequencing a 604 base pair (bp) fragment of Pvmdr1 for SNP haplotype generation and the amplification of eight microsatellite (MS) loci located across the genome on eight different chromosomes. No detectable CQ resistance was found in the patient samples tested in this study, and there was no evidence of previously correlated Pvmdr1 resistance alleles gaining in frequency in the parasite population. However, valuable population level genetic diversity information was obtained, and this pilot study paves the way for future studies on the impact of primaquine (PQ) on relapsing infections.

\section{Methods}

\section{Field location and study design}

Samples were collected from patients attending the Central Malaria Laboratory (CML) in George Town, Chennai, in the state of Tamil Nadu, southeast India. George Town, a predominantly residential/commercial area of the city, is densely populated $(\sim 51,000$ people $/ \mathrm{km})$ and mainly comprised of business community members of a high socio-economic status. However, this area also attracts a large number of laborers mainly from the southern districts of Tamil Nadu, and the population is also composed of different ethnic groups from other states of India such as Rajasthan, Bihar, Gujarat, Haryana, Maharashtra, Uttar Pradesh and Nepal. Immigration combined with rapid urbanization within the catchment area of the CML ( $2 \mathrm{~km}$ or 100,000 residents) maintains local endemicity in this region. The CML is under the administrative control of the Health Department of the Municipal Corporation of Chennai and serves individuals from all economic strata through passive case detection (PCD). Approximately 15,000 blood smear examinations are performed each year.

Samples collected for this study had ethical clearance from the Ethical Committee of the National Institute of Malaria Research (ICMR) and the Institutional Review Board of New York University Langone Medical Center. 
All participants provided informed consent and/or assent. Inclusion criteria were specific for each study and are detailed below. Patients were treated as per the National Vector Borne Disease Control Programme (NVBDCP) guidelines in India as given in the study methods.

\section{In vivo therapeutic efficacy study}

A total of 856 patients were screened for malaria at the CML Malaria Clinic between the start of enrollment in mid-July 2010 and the completion of this study in midNovember 2010. Of these patients, 125 were enrolled in the 28-day in vivo therapeutic efficacy study (Figure 1A). Inclusion criteria included: $>10$ and $<70$ years of age, non-gravid women, patients with no existing concurrent infection(s) (including mixed species determined by microscopy), parasitaemia $>500$ asexual parasites $/ \mu$ blood (to ensure enough parasite DNA for downstream experiments), no administration of anti-malarials or antibiotics within three weeks of enrollment and consent for 28-day follow up. The CML utilizes convenience sampling, which often results in an over-representation of males in the study population; a higher frequency of women and children seek treatment at private clinics. Subjects were enrolled on Day 0 and administered 1,500 mg of CQ over 3 days administered by the CML clinic. Subjects were followed on Days 1,
$2,3,7,14,21,28$ and by passive case surveillance for any clinic visits beyond Day 28 (Day of Recurrence), ranging from 44 to 148 days post-enrollment. PQ $(0.25 \mathrm{mg} / \mathrm{kg})$ for radical cure was given on Day 28 and administered for 14 days under direct observation of a medical officer. For each subject, thick and thin smears were collected on Days 0, 2, 7, 14, 21 and 28 and examined by expert microscopists. Blood spots for DNA extraction and isolate genotyping were collected before treatment on Day 0 and on any subsequent day when the subject presented with fever.

To investigate patterns in genetic diversity between infection pairs, DNA was extracted from blood spots and used for (i) amplification and sequencing of a 604 base pair (bp) fragment of $P v m d r 1$ to determine the presence of SNPs previously associated with CQ resistance (T958M, Y976F and F1076L) [35] and (ii) MS genotyping to describe the relatedness between the pairs [42], described below.

\section{In vitro $\mathrm{CQ}$ drug assay}

The in vitro drug study, carried out in August 2009 and August-September 2010, enrolled 96 subjects (Figure 1B). Inclusion criteria included: $>1$ and $<70$ years of age, nongravid women, patients with no existing concurrent infection(s) (including mixed species determined by microscopy) and no administration of anti-malarials or antibiotics within

\section{A. In vivo therapeutic efficacy study}

Sample collection and treatment:

\begin{tabular}{|l|}
\hline \\
Withdraws ( $\mathbf{n}=\mathbf{5}) ;$ \\
Loss to follow up ( $\mathbf{n}=\mathbf{1 3})$
\end{tabular}

\section{B. In vitro drug assay}

Sample collection and treatment:

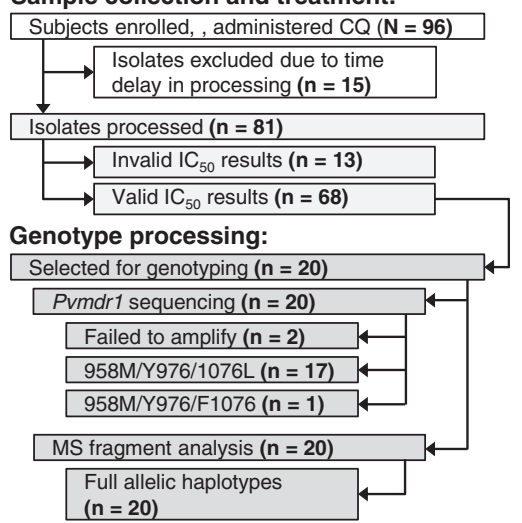

Figure 1 Study profiles for in vivo therapeutic efficacy study (A) and in vitro drug assay (B). Profiles detail enrollment, experimental design and sample utilization for both studies. Abbreviations: CQ (chloroquine), PQ (primaquine), MS (microsatellites), D (day), and Rec (recurrence) and pvmdr1 (Plasmodium vivax multidrug resistance gene 1). 
3 weeks of enrollment. Due to the quantity of material collected, no inclusion criterion was established for parasitaemia level. For each subject, thick and thin smears and 3-4 $\mathrm{ml}$ of intravenous blood were collected. For each 3-4 $\mathrm{ml}$ of patient venous blood, host white blood cells were removed by CF11 filtration within three hours of collection [43], and the packed red blood cells were divided as follows: $1 \mathrm{ml}$ was cryopreserved in Glycerolyte 57 solution (Baxter, Deerfield, IL), $200 \mu \mathrm{l}$ were spotted onto filter paper and $800 \mu \mathrm{l}$ was used for the in vitro drug susceptibility assay as described $[44,45]$. Parasite counts taken before and after CF11 filtration revealed a significant reduction in mature blood stage parasites; consequently, no additional synchronization was performed in an effort to maximize immature ring-stage count.

Drug plates were prepared by coating the wells with CQ di-phosphate (Sigma) dissolved in water, serially diluted from a maximum concentration of $514 \mathrm{ng} / \mathrm{ml}$ to a minimum of $8 \mathrm{ng} / \mathrm{ml}$, dried in a non-humidified incubator overnight at $37^{\circ} \mathrm{C}$, and stored in the dark at $4^{\circ} \mathrm{C}$. Batches of plates were tested for efficacy of the drug by using two $P$. falciparum lab strains from the National Institute of Malaria Research (NIMR) Parasite Bank, MRC2 (CQ sensitive) and RKL9 (CQ resistant). Approximately $200 \mu \mathrm{l}$ of a $2 \%$ haematocrit blood medium mixture consisting of McCoy's 5A media (Gibco) and 20\% AB + human serum was added to each well, including control wells, and patient samples were tested in duplicate. Plates were incubated at $37^{\circ} \mathrm{C}$ in a candle jar for 36 hours, a thick smear prepared for each of the wells, stained with Giemsa or Jaswant-Singh-Bhattacherji (JSB) stain and parasitaemia quantified by microscopy. The number of schizonts per 200 asexual stage parasites was determined for each slide and the result for each drug concentration normalized to the control well. Only healthy schizonts with six or more distinct chromatin dots were quantified. Dose-response data were then analyzed using nonlinear regression analysis (HN-NonLin v.1.1, USAMC-AFRIMS, Bangkok, Thailand), and the $50 \%$ inhibitory concentration $\left(\mathrm{IC}_{50}\right)$ obtained.

A selection of isolates used in the in vitro drug assay was identified for further characterization by genotyping. Similar to the in vivo assay isolates, DNA was extracted from blood spots and used for (i) amplification and sequencing of a 604 base pair (bp) fragment of Pvmdr1 [35] and (ii) MS genotyping to describe the relatedness between the pairs [42], as described below.

\section{Genetic diversity analysis}

$D N A$ extraction and species-specific $P C R$

DNA extraction was performed using QIAamp ${ }^{\odot}$ DNA Mini Kit (Qiagen Inc., Valencia, CA). Species-specific polymerase chain reaction (PCR) [46] was used to confirm $P$. vivax microscopy diagnosis and rule out mixed species infections.

\section{Amplification and sequencing of Pvmdr1}

Previously published primers and methods were used to amplify a 604 base pair (bp) fragment of Pvmdr1 [35], capturing three single nucleotide polymorphisms that cause non-synonymous amino acid changes (T958M, Y976F and F1076L) associated with CQ resistance in $P$. vivax in some studies. PCR products were analyzed by gel electrophoresis and sequenced on an ABI 3730xl sequencer (Applied Biosystems, Foster City, CA) with $\geq 2 \mathrm{x}$ coverage using BigDye Terminator $\mathrm{v} 3.1$ and using both forward and reverse primers. Sequences were viewed using Chromas 2.33 (Technelysium Pvt Ltd), and subsequently aligned using Seaview 4 [47].

\section{Microsatellite amplification and analysis}

Eight MS markers [42] were selected from the literature (Additional file 1) after consideration of recommended guidelines [48]. Using previously published methods and PCR conditions, MS were amplified in $20 \mu \mathrm{l}$ reactions with $\sim 40 \mathrm{ng}$ of extracted DNA using. All reactions were performed individually and not in multiplex. Forward $\left(5^{\prime}-3^{\prime}\right)$ oligonucleotides were labeled with the phosphoramidite conjugate 6-FAM (Eurofins MWG Operon, Huntsville, AL) and the P. vivax laboratory strain Salvador I was used as a positive control. PCR amplicons were analyzed on an ABI 3730xl sequencer using GeneScan-500 LIZ size standard (Applied Biosystems, Foster City, CA) for size determination. Bands $<200$ relative fluorescence units (rfu) were excluded and used to define the background. Isolates with greater than one locus having multiple peaks were defined as multiclonal infections, and minor peaks less than $1 / 3$ the height of the major peak were excluded [49].

Expected heterozygosity $\left(H_{e}\right)$ was used to quantify the amount of genetic diversity within each MS locus in this study, but not across compiled haplotypes of loci due to low sample size. $H_{e}$ was calculated with the following standard formula:

$$
H_{e}=\left[\frac{n}{n-1}\right]\left[1-\sum_{i=1}^{n} p_{i}^{2}\right],
$$

where $n$ is the number of infections sampled and $p_{i}$ is the frequency of the $i^{\text {th }}$ allele. For the maximum expected probability of allelic combinations ranging from one to eight loci, let $P$ equal the maximum probability of $A$, highest frequency alleles, to the $n^{\text {th }}$ locus, defined as:

$$
\left.\mathrm{P}\left(\mathrm{A}_{1} \cap \mathrm{A}_{2} \cdots \cap \mathrm{A}_{n}\right)=\mathrm{P}\left(\mathrm{A}_{1}\right) \mathrm{P}\left(\mathrm{A}_{2}\right) \cdots \mathrm{P}\left(\mathrm{A}_{n}\right)\right) .
$$

Due to the small sample size, it is not possible to accurately estimate the allele frequencies for the population. To account for this potential error, the standard deviation (SD) of the allele frequency was estimated by a parametric bootstrap procedure, which generates random samples from a population assumed to have allele 
frequencies equal to their maximum-likelihood values. The SD of each allele frequency was then estimated from the resulting distribution of allele frequencies $[50,51]$. The resulting SD was used to calculate the standard error (SE) by: $S E=S D / \sqrt{ } n$, where $n$ is equal to the number of samples with a specific allele.

\section{Results}

\section{In vivo therapeutic efficacy study}

To determine the in vivo therapeutic efficacy of CQ, 125 patients were enrolled in a 28-day follow up study at the
CML in George Town, Chennai. Demographic and clinical data is provided in Table 1A. A total of 107 (85.6\%) subjects completed the 28-day follow up, five subjects (4.0\%) withdrew from the study and $13(10.4 \%)$ were lost to follow up (Figure 1A). No fever was observed after 48 hours (Day 2) for all 107 subjects completing the study. Eighty-eight (82.2\%) subjects had no sexual or asexual parasites by Day 2, and 17 subjects (15.9\%) had no sexual or asexual parasites by Day 7. Two (1.9\%) subjects remained positive for sexual stage parasites until a time between Day 7 and Day 14, at which point all patients remained negative for $P$. vivax for the remainder of the

Table 1 Demographic and clinical data for the in vivo therapeutic efficacy study (A) and the in vitro drug assay (B)

\begin{tabular}{|c|c|c|c|c|c|}
\hline \multicolumn{3}{|c|}{ A. In vivo therapeutic efficacy study } & \multicolumn{3}{|c|}{ B. In vitro drug assay } \\
\hline \multicolumn{2}{|c|}{ Characteristics } & \multirow{2}{*}{$\frac{(\mathbf{N}=\mathbf{1 2 5})}{120(95.0)}$} & \multicolumn{2}{|c|}{ Characteristics } & \multirow{2}{*}{$\begin{array}{l}(\mathbf{N}=\mathbf{9 6}) \\
85(88.5)\end{array}$} \\
\hline Sex [n (\%)] & Male & & $\operatorname{Sex}[n(\%)]$ & Male & \\
\hline & Female & $5(5.0)$ & & Female & $11(11.5)$ \\
\hline \multirow[t]{5}{*}{ Wt (kg) } & & & Age (yr) & & \\
\hline & Mean & 52.8 & & Mean & 23.9 \\
\hline & Range & $5.0-77.0$ & & Range & $7-53$ \\
\hline & SD & \pm 10.4 & & SD & 8.3 \\
\hline & $95 \% \mathrm{Cl}$ & $51.0-54.7$ & & $95 \% \mathrm{Cl}$ & $22.2-25.6$ \\
\hline \multirow[t]{5}{*}{ Age (yr) } & & & Parasite co & & \\
\hline & Mean & 25.9 & & Mean & 6348.6 \\
\hline & Range & $13-66$ & & Range & $480-21,522$ \\
\hline & SD & 10.5 & & SD & 4390.8 \\
\hline & $95 \% \mathrm{Cl}$ & $24.0-27.8$ & & $95 \% \mathrm{Cl}$ & $5,172.8-7,524.5$ \\
\hline \multicolumn{3}{|c|}{ Body temperature $\left({ }^{\circ} \mathrm{F}\right)$} & Parasitaem & & \\
\hline & Mean & 98.5 & & Mean & 0.163 \\
\hline & Range & $95.4-104.4$ & & Range & $0.032-0.445$ \\
\hline & SD & 2.2 & & SD & 0.094 \\
\hline & $95 \% \mathrm{Cl}$ & $98.1-98.9$ & & $95 \% \mathrm{Cl}$ & $0.122-0.203$ \\
\hline \multirow[t]{5}{*}{ Haemoglobi } & & & Rings (\%) & & \\
\hline & Mean & 14.4 & & Mean & 3.2 \\
\hline & Range & $12.0-16.6$ & & Range & $0.0-33.3$ \\
\hline & SD & 1.0 & & SD & 5.9 \\
\hline & $95 \% \mathrm{Cl}$ & $14.2-14.6$ & & $95 \% \mathrm{Cl}$ & $1.9-4.6$ \\
\hline \multirow[t]{10}{*}{ Parasite cou } & & & Trophozoit & & \\
\hline & Mean & 9049.2 & & Mean & 91.0 \\
\hline & Range & $1,000-57,200$ & & Range & 58.3-100.0 \\
\hline & SD & 6697.3 & & SD & 11.6 \\
\hline & $95 \% \mathrm{Cl}$ & $5,243.4-7,624.4$ & & $95 \% \mathrm{Cl}$ & 88.4-93.6 \\
\hline & & & Schizonts ( & & \\
\hline & & & & Mean & 5.8 \\
\hline & & & & Range & $0.0-33.3$ \\
\hline & & & & SD & 1.1 \\
\hline & & & & $95 \% \mathrm{Cl}$ & $3.6-7.9$ \\
\hline
\end{tabular}


28-day study (Figure 2). Though the study was completed on Day 28, passive case surveillance continued to monitor the enrolled subjects until four months postenrollment. Twenty-two of the subjects who had completed the 28-day follow up presented with malaria-like symptoms at a time-point after Day 28. These 22 subjects were tested for malaria by microscopy and 17 subjects were found to have recurrent $P$. vivax infections on a day ranging from 44 to 148 post-enrollment (termed "Day of Recurrence") (Figure 1A).

\section{Genetic diversity and Pvmdr1 genotyping of in vivo isolates}

Day 0 infections that were subsequently positive on Day 2 and/or Day of Recurrence were genotyped. Despite detecting two positive cases on Day 7, no blood was collected due to an absence of fever (see Methods), so these infections were excluded from genotyping experiments. In total, 69 isolates (33 Day 0, 19 Day 2 and 17 Day of Recurrence) were selected for genotyping in the following combinations: (1) Day 0 and 2 paired-infection ( $\mathrm{n}=15,30$ isolates); (2) Day 0, 2 and 7 paired-infection ( $\mathrm{n}=1,2$ isolates); (3) Day 0, 2, 7 and Day of Recurrence paired-infection ( $\mathrm{n}=1,3$ isolates); (4) Day 0, 2 and Day of Recurrence ( $n=3,6$ isolates); and (5) 14 Day 0 and Day of Recurrence paired-infection ( $\mathrm{n}=14,28$ isolates) (Figure 1A). No Day 2 isolates successfully amplified for genotyping or sequencing, despite successful amplification by species-specific diagnostic PCR. Consequently, the

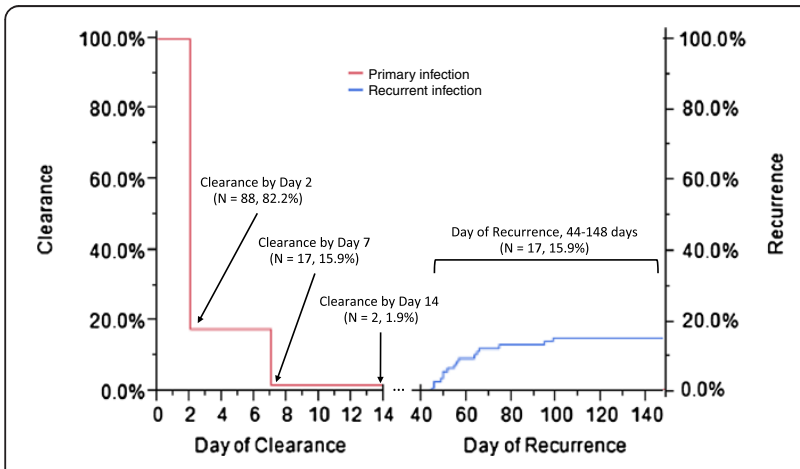

Figure 2 Clearance and recurrence plot of the infections observed in the in vivo therapeutic efficacy study. Of the 125 subjects enrolled in this study 107 completed the 28-day follow up. An absence of fever within 48 hours (Day 2) was observed for all 107 subjects completing the study. Eighty-eight (82.2\%) subjects were aparasitaemic for both sexual and asexual morphological stages by Day 2 and 17 (15.9\%) by Day 7 (Primary infection, red line). Two (1.9\%) subjects remained positive for sexual stage parasites until a time between Day 7 and Day 14, at which point no parasites remained detectable by microscopy (Primary infection, red line). Of these 107 subjects, 17 subjects were parasite positive at a time point beyond the 28-day enrollment period, ranging from 44-148 days post-enrollment (Recurrent infection, blue line). only paired-infection suitable for genetic analysis were Day $0(\mathrm{n}=33)$ and Day of Recurrence $(\mathrm{n}=17)$ (Figure 1A).

A 604bp fragment of Pvmdr1 was successfully amplified and sequenced for all Day 0 isolates $(n=33)$; all isolates (100\%) were identified as having the mutant 958M/ Y976/1076L haplotype. For the Day of Recurrence isolates, 15 of the 17 isolates successfully amplified and were sequenced; 14 (93.3\%) of these were identified as the mutant 958M/Y976/1076L haplotype and 1 (6.7\%) as the mutant 958M/Y976/F1076 haplotype (Table 2). No new SNPs were detected and sequences have been deposited in GenBank (Accession nos: KC818367-KC818412).

Eight MS markers were used to determine the genetic diversity of the Day $0(n=33)$ and Day of Recurrence $(\mathrm{n}=17$ ) isolates (Figure 1A). MS haplotypes were found to be extremely diverse with no common haplotypes within a single group (within the Day 0 samples or within the Day of Recurrence samples). However, when comparing paired isolates collected from the same individual (on Day 0 paired with Day of Recurrence), there were distinct patterns of relatedness, likely indicating relapsing or recrudescing parasite infections. Of the 17 subjects that were parasite positive on Day of Recurrence, MS haplotypes revealed that $58.8 \%(n=9)$ of the infection pairs were related to the Day 0 sample with $\geq 75 \%$ haplotype similarity (same allele at six or more loci) between samples. In fact, there were six instances where all eight (100\%) MS alleles matched exactly, one instance where seven $(87.5 \%)$ alleles matched and two instances with six (75.0\%) alleles matched (Table 3 ). The probability of detecting identical allelic combinations was calculated for each paired sample based on the number of alleles repeated and the observed frequency of each specific allele present within the population (see Methods for calculation parameters and equation). Due to the extensive genetic diversity within the local $P$. vivax parasite population, it seems unlikely that any Day of Recurrence infection identified as having $\geq 75 \%$ relatedness between sample pairs was due to a new infection, with a probability ranging from 0.001 to $1.98 \mathrm{E}-05$; rather it is more likely to be the result of a relapsing or recrudescing parasite infection.

Although all 17 subjects with recurrent infections began the 14-day PQ drug regimen during their enrollment in the 28-day in vivo study, only 10 were known to complete the recommended therapy. MS data from this study indicated that six of the nine subjects with highly related paired-infections did complete radical PQ therapy. This finding may support recurrence via recrudescence if the parasite population remains susceptible to the drug, or recurrence via relapse if the parasite population has become tolerant or resistant (Table 3).

Of these 17 paired-infections, 13 (76.5\%) were single infections on both Day 0 and Day of Recurrence, while two (11.8\%) were single on Day 0 and then multiclonal 
Table 2 Genotyping results from isolates in the in vivo therapeutic efficacy study and in vitro drug assay

\begin{tabular}{|c|c|c|c|c|c|c|c|c|c|}
\hline \multirow{2}{*}{\multicolumn{2}{|c|}{ Study }} & \multirow[b]{2}{*}{$\begin{array}{l}\text { Subjects } \\
\text { enrolled }(\mathrm{N})\end{array}$} & \multicolumn{3}{|c|}{ Pvmdr1 haplotypes ${ }^{a}$} & \multicolumn{4}{|c|}{ Microsatellite genotyping } \\
\hline & & & $\begin{array}{l}\text { Isolates successfully } \\
\text { genotyped (n) }\end{array}$ & $\begin{array}{c}\text { 958M/Y976/ } \\
1076 \mathrm{~L}(\mathrm{n}(\%))\end{array}$ & $\begin{array}{c}958 \mathrm{M} / \mathrm{Y} 976 / \\
\mathrm{F} 1076(\mathrm{n}(\%))\end{array}$ & $\begin{array}{l}\text { Isolates successfully } \\
\text { genotyped (n) }\end{array}$ & $\begin{array}{l}\text { Multiclonal } \\
\text { infections } \\
(\mathrm{n}(\%))\end{array}$ & $\begin{array}{c}\text { Clones } \\
\text { (n) }\end{array}$ & $\begin{array}{l}\text { Multiplicity of } \\
\text { infection }^{\mathrm{c}}\end{array}$ \\
\hline \multicolumn{10}{|c|}{ in vivo therapeutic efficacy: } \\
\hline & Day 0 & 125 & 33 & $33(100)$ & $0(0.0)$ & 33 & $5(15.2)$ & 38 & 1.15 \\
\hline & Day 3 & 19 & 0 & - & - & 0 & - & - & - \\
\hline & $\begin{array}{l}\text { Day } \\
\text { Other }\end{array}$ & 17 & 15 & $14(93.3)$ & $1(6.7)$ & 17 & $3^{b}(17.6)$ & 21 & 1.24 \\
\hline & Total & 125 & 48 & $47(97.9)$ & $1(2.1)$ & 50 & $8(16.0)$ & 59 & 1.18 \\
\hline \multicolumn{10}{|c|}{ in vitro drug assay: } \\
\hline & $\begin{array}{c}\text { Group } \\
1\end{array}$ & 51 & 9 & $8(88.9)$ & $1(11.1)$ & 10 & $4(40.0)$ & 14 & 1.40 \\
\hline & $\begin{array}{l}\text { Group } \\
2\end{array}$ & 17 & 9 & $9(100)$ & $0(0.0)$ & 10 & $2(20.0)$ & 12 & 1.20 \\
\hline & Total & 68 & 18 & $17(94.4)$ & $1(5.6)$ & 20 & $6(30.0)$ & 26 & 1.30 \\
\hline
\end{tabular}

${ }^{a}$ GenBank accession nos: KC818349-KC818412; Pvmdr1 haplotype of the CQ sensitive Salvador I reference strain is T958/Y976/F1076.

${ }^{b}$ Of the three multiclonal infections, two had two alleles at more than one locus (double infection) and one had three alleles at more than one locus (triple infection).

'Multiplicity of infection is the total number of clones detected divided by the total number of infections.

on Day of Recurrence, one (5.9\%) was multiclonal on Day 0 and then single on Day of Recurrence, and one (5.9\%) was multiclonal on both Day 0 and Day of Recurrence. In all four cases, all possible haplotype combinations were made and compared between paired-infections. Given the high allelic diversity, only two of the four multiclonal infections shared $\geq 75 \%$ haplotype similarity, with both cases sharing six of eight alleles (Table 3).

\section{In vitro $\mathrm{CQ}$ drug assay}

A total of 96 subjects were enrolled by PCD at the CML to assay for susceptibility to CQ in vitro. Demographic and clinical data is provided in Table $1 \mathrm{~B}$. An in vitro CQ drug assay completed on 81 isolates gave reliable $\mathrm{IC}_{50}$ values for 68 isolates (Figure $1 \mathrm{~B}$ ). $\mathrm{IC}_{50}$ values were low for all isolates, ranging from 7.8-30.2 $\mathrm{nM}$. When plotted the distribution of the $\mathrm{IC}_{50}$ values is a non-linear curve, with a geometric mean of $16.3 \mathrm{nM}$ (95\% CI: 14.9-17.8 nM).

Unlike reports from other vivax malaria endemic regions, the percentage of ring-stage parasites upon collection and processing was low. The mean parasitaemia was $0.163 \%$ (95\% CI: $0.122-0.203 \%$ ) and was largely dominated by trophozoite-stage parasites (90.0\%, 95\% CI: 88.493.6\%). This resulted in a reduced ring-stage inoculation of in vitro culture (Mean: 3.23\%, 95\% CI: 1.90-4.58\%). After 36 hours of in vitro culture, no correlation between $\mathrm{IC}_{50}$ values and the percentage of ring-stage parasites prior to culture was observed ( $\mathrm{r}_{\text {sadj: }}$-0.00063, $\mathrm{p}=0.3307$ ).

\section{Genetic diversity and Pvmdr1 genotype of in vitro samples}

The interquartile range of the $\mathrm{IC}_{50}$ values was used to group isolates into either Group 1 ( $\mathrm{n}=40$, IQR $<75 \%=7.8$ to 21.9 ) or Group $2(\mathrm{n}=18, \mathrm{IQR} \geq 75 \%=22.1$ to 30.2$)$, and

Table 3 Microsatellite allele sharing between paired-infections, and the calculated maximum expected probability of sharing a specific combination of alleles

\begin{tabular}{ccc}
\hline $\begin{array}{c}\text { Possible alleles shared } \\
\text { between pairs (n/total) }\end{array}$ & $\begin{array}{c}\text { Infection(s) with allele pair } \\
\text { profile (n/total) }\end{array}$ & $\begin{array}{c}\text { Maximum expected } \\
\text { probability (SE) }\end{array}$ \\
\hline $1 / 8$ & $4 / 17$ & $0.422(0.410,0.434)$ \\
$2 / 8$ & $1 / 17$ & $0.119(0.11,0.128)$ \\
$3 / 8$ & $1 / 17$ & $0.032(0.028,0.036)$ \\
$4 / 8$ & $1 / 17$ & $0.008(0.007,0.010)$ \\
$5 / 8$ & $1 / 17$ & $0.002(0.001,0.003)$ \\
$6 / 8$ & $2 / 17$ & $5.23 \mathrm{E}-04(3.90 \mathrm{E}-04,6.92 \mathrm{E}-04)$ \\
$7 / 8$ & $1 / 17$ & $1.23 \mathrm{E}-04(8.60 \mathrm{E}-04,1.72 \mathrm{E}-04)$ \\
$8 / 8$ & $6 / 17$ & $2.68 \mathrm{E}-05(1.76 \mathrm{E}-05,4.00 \mathrm{E}-05)$ \\
\hline
\end{tabular}


a total of 20 isolates (10 from each group) were selected for further analysis (Figure 1B). Genotyping isolates across a range of $\mathrm{IC}_{50}$ values helped to gather evidence of Pvmdr1 resistance alleles gaining in frequency in the parasite population.

Pvmdr1 was successfully amplified and sequenced for nine of the 10 isolates in Group 1; eight of these (88.9\%) were identified as having the mutant $958 \mathrm{M} / \mathrm{Y976} / 1076 \mathrm{~L}$ haplotype and 1 (11.1\%) as having the mutant 958M/Y976/ F1076 haplotype. A similarly dominant pattern of the mutant 958M/Y976/1076L haplotype was observed in nine of the Group 2 isolates (100\%). These sequences have been deposited in GenBank (Accession nos: KC818349KC818366).

The same 20 isolates were genotyped using eight polymorphic MS to obtain background genetic diversity data in the form of the mean number of alleles per locus, the distribution of alleles per locus and the multiplicity of infection (MOI) (Table 2). Both groups had high levels of genetic diversity with no common MS haplotypes within or between the two groups. Though expected given the small sample size, there was no significant difference between the mean number of alleles per locus for Group 1 isolates was 5.89 (range $=4$ to $9, \mathrm{SD}=1.55$ ) and for Group 2 isolates 6.5 (range $=3$ to $8, \mathrm{SD}=1.93$ ). The distribution of specific alleles between the two groups also did not differ significantly (ranging from $\mathrm{r}^{2}=0.17$ and $\mathrm{p}=0.18$, to $\mathrm{r}^{2}=0.06$ and $\left.\mathrm{p}=0.60\right)$; that is, there did not appear to be a distribution of alleles that was specific to either group. Similarly, there was no significant difference between the total number of clones, multiclonal infections or MOI between Group $1(n=\geq 14, n=4$ and MOI $=1.40$, respectively) and Group $2(n=\geq 12, n=2$ and MOI $=1.20$, respectively) (Table 2$)$.

\section{A city-wide view of $P$. vivax genetic diversity in Chennai} Since the subjects for the in vivo and in vitro studies were collected from the same clinic, with sample collection occurring during the same period (2009-2010), MS data were collated into one database to provide a more comprehensive perspective of the parasite population- level diversity. In total 70 samples were genotyped, 20 from the in vitro CQ drug assay and 50 samples from the in vivo therapeutic efficacy study. For each locus the number of alleles, size range, frequency of the most common allele, expected heterozygosity $\left(H_{e}\right)$ and the MOI was calculated (Table 4). On the whole, the mean number of alleles per locus was high (Mean $=13.3, \mathrm{SD}=$ 4.71, range $=5$ to 20), indicating high levels of $P$. vivax genetic diversity, which was confirmed by calculating $H_{e}$ (Mean $=0.856, \mathrm{SD}=0.063$, range $=0.729$ to 0.912 ). As expected, the number of alleles per locus was positively correlated with the $H_{e}\left(\mathrm{p}=0.0008, \mathrm{r}^{2}=0.86\right.$, ANOVA) and negatively correlated with the frequency of the most common allele per locus ( $p=0.0029, \mathrm{r}^{2}=0.79$, ANOVA). Consistent with this order, the frequency of the most common allele per locus was also negatively correlated with the $H_{e}\left(\mathrm{p}=0.0002, \mathrm{r}^{2}=0.92\right.$, ANOVA $)$ and the MOI $\left(\mathrm{p}=0.0206, \mathrm{r}^{2}=0.62\right.$, ANOVA). MOI was only significantly correlated with the frequency of the most common alleles for each locus, indicating that it is not necessarily the amount of diversity present within a high transmission population, but rather how the diversity is dispersed within the population that influences the accumulation of multiple clones within a single infection.

\section{Conclusions}

In this study, $P$. vivax CQ sensitivity was investigated among infected patients in Chennai, Tamil Nadu. A longitudinal in vivo efficacy study was used to monitor the clearance of parasites and recurrence of infection, and an in vitro CQ drug assay was used to monitor the doseresponse effect on parasites isolated from patient samples (Table 1 and Figure 1). Molecular genotyping was used in both studies to investigate the genetic structure of the parasites and to determine if a correlation between parasite genetic diversity and drug susceptibility to $\mathrm{CQ}$ existed.

The in vivo efficacy study demonstrated $P$. vivax sensitivity to CQ in Chennai. Of the 125 subjects enrolled, 107 completed follow up and were microscopy negative for asexual parasites by Day 7; however, two

Table 4 Genetic diversity of eight $\boldsymbol{P}$. vivax microsatellite loci in the study population

\begin{tabular}{lccccc}
\hline Locus & No. of alleles & Size range & Frequency of most common allele (SD) & Multiplicity of infection & $\boldsymbol{H}_{\boldsymbol{e}}$ \\
\hline MS2 & 10 & $188-250$ & $0.281(0.057)$ & 1.15 & 1.13 \\
MS3 & 10 & $169-199$ & $0.250(0.055)$ & 1.09 & 0.807 \\
MS6 & 15 & $197-269$ & $0.250(0.055)$ & 1.01 & 1.18 \\
MS7 & 5 & $131-143$ & $0.422(0.062)$ & 1.13 & 0.882 \\
MS9 & 15 & $137-197$ & $0.226(0.056)$ & 1.10 & 0.732 \\
MS10 & 17 & $159-250$ & $0.219(0.052)$ & 0.906 \\
MS12 & 14 & $183-311$ & $0.266(0.056)$ & 0.14 & 0.862 \\
MS20 & 20 & $160-223$ & $0.234(0.053)$ & &
\end{tabular}


subjects remained positive for sexual parasites until a time prior to the Day 14 collection. Seventeen subjects remained microscopy negative until a time point after Day 28, called Day of Recurrence, which ranged from 44 to 148 days after the initial enrollment (Day 0) (Figure 2). Isolates from Day 0 and Day of Recurrence were genotyped to determine relatedness between the infecting clones. Of the 17 paired-infections, nine were found to share $\geq 75 \%$ of the same alleles. Six (66.7\%) of the nine subjects experiencing recurrent infections were known to take PQ radical treatment beginning on Day 28 of this study (Table 3). Though no distinction can be made on whether or not these recurrent infections were due to a relapse, recrudescence or reinfection, microscopy examination indicated parasite clearance by Day 7 and the time-to-recurrence for these infections was within the expected timeframe of a tropical relapse [52,53]. Other studies in India have reported variable $P$. vivax relapse rates, between 2.2 and $40.1 \%$, which may be linked with the geographic distribution of relapsing phenotypes [54-57]. However, as recently highlighted by White (2011), little is known about these relapsing phenotypes in India, which is a serious cause for concern given that India harbors a significant global $P$. vivax burden [58,59]. In an effort to understand these phenotypes, cross-sectional, longitudinal and clinic epidemiological studies are underway at three sentinel sites in India, as part of the Center for the Study of Complex Malaria in India (CSCMi), an International Center of Excellence in Malaria Research [60].

Results from the in vitro CQ drug assay, which measures the inhibitory concentration $\left(\mathrm{IC}_{50}\right)$ of drug needed to prevent parasite growth, also revealed $P$. vivax sensitivity to $\mathrm{CQ}$ in the parasite isolates collected from Chennai. $\mathrm{IC}_{50}$ values from this study ranged from 7.8$30.2 \mathrm{nM}(\mathrm{N}=68)$, which is significantly lower than the $220 \mathrm{nM}$ cutoff for CQ resistance define by Suwanarusk et al. [35] in Indonesia and Thailand, as well as the 100 nM cutoff for CQ resistance defined by Druilhe et al. [61] in isolates from Myanmar. Regional differences in the above cutoff values are most likely due to methodological differences. Fragment sequencing of $P v m d r 1$ in both studies revealed that the mutant 958M/Y976/1076L was the dominant haplotype, while the mutant 958M/ Y976/F1076 was the minor haplotype (Table 2). The majority of isolates containing the $1076 \mathrm{~L}$ mutation, which is highly prevalent across the globe, is actually predominantly found in regions with $P$. vivax CQsensitivity [26-28,35,37,62,63]. The detection of these two haplotypes is consistent with a recent report in nearby Nepal, which may indicate relatedness between the parasite populations in India and Nepal [63]. Similar to a genotyping study in Kolkata [29], the mutant
976F was not detected in any of the Chennai isolates tested in these two studies (Table 2). Previous studies have reported that this mutation is linked with drug resistance [35,63]; however, subsequent studies have been unable to confirm this association [64-66]. MS genotyping of these $P$. vivax isolates revealed an unconstrained and highly diverse population of parasites, with no correlation to Pvmdr1 haplotypes or $\mathrm{IC}_{50}$ values. Rather, valuable information was gained about the population-level genetic diversity of extant $P$. vivax, which will help to direct future population diversity studies with larger sample sizes.

Considering the highly endemic nature of $P$. vivax in India and proximity to other countries such as Myanmar, Thailand and Indonesia, the emergence of $P$. vivax CQ resistance is a persistent threat. Although there are few case reports of $P$. vivax resistance to CQ in India, the potential for a similar devastating situation as happened with the emergence of CQ resistant $P$. vivax in Southeast Asia should encourage constant surveillance. Urban malaria epicenters, like Chennai, are of particular interest because the local incidence is not only shaped by common environmental factors, such as the seasonality of monsoons and the development of insecticide resistance, but also by population density, rapid urbanization, sanitation practices and inaccessibility to many sites for continuous monitoring. Though it is not completely understood why $P$. vivax drug resistance has yet to sweep across India, further investigation on this subject is currently underway as part of CSCMi. As India moves into the pre-elimination phase, the need for increased surveillance of drug resistance has never been more important.

\section{Additional file}

Additional file 1: Primer information for microsatellites used for genotyping Plasmodium vivax parasites.

\section{Competing interests}

The authors declare no competing interests.

\section{Authors' contributions}

$\mathrm{AE}$ and $\mathrm{JMC}$ designed the study protocol and provided training for the study; SS, SC undertook sample collection, in vitro drug tests and analysis with help from JC and AE. PLS, SC and SS performed molecular biology experiments; PLS undertook data and statistical analysis; AE, JKD and KJR organized logistics for students, provided access to laboratory space and equipment and provide expertise to facilitate the study protocol; NM and NS provided mentoring for SS; PLS, SS, SC, JC and AE wrote the manuscript. All authors read and approved the final manuscript.

\section{Authors' information}

Sneh Shalini, Saumyadripta Chaudhuri and Patrick L Sutton joint first author.

\section{Acknowledgements}

We thank the Director, NIMR (ICMR) for providing the necessary facilities and support. The technical support of Mr. N. Bhaskar and Ms. B. Reeta, Technicians and the staff of NIMR field unit are gratefully acknowledged. This study was supported with funds from a Fogarty International Center Global Infectious 
Disease training grant (D43 TW007884). The content of this manuscript is solely the responsibility of the authors and does not necessarily represent the official views of the Fogarty International Center or the National Institutes of Health. We thank Drs. Bruce Russell and Simon Kang'a for technical support and Dr. Steven Sullivan for editing and proofreading the manuscript. This work would not have been possible without the support of the health staff of the Corporation of Chennai and the patients involved in the study. This paper bears the NIMR publication committee clearance number 006/2013.

\section{Author details}

${ }^{1}$ National Institute of Malaria Research (Indian Council of Medical Research), Sector 8 Dwarka, New Delhi 110 077, India. ${ }^{2}$ Department of Biology, Center for Genomics and Systems Biology, New York University, 12 Waverly Place, New York, NY 10003, USA. ${ }^{3}$ School of Studies in Biochemistry, Jiwaji University, Gwalior 474 011, India. ${ }^{4}$ National Institute of Epidemiology (Indian Council of Medical Research), Second Main Road, Tamil Nadu Housing Board, Ayapakkam, Chennai 600 077, India. ${ }^{5}$ National Institute of Malaria Research (Indian Council of Medical Research), National Institute of Epidemiology Campus, Second Main Road, Tamil Nadu Housing Board, Ayapakkam, Chennai 600 077, Tamil Nadu, India.

Received: 10 January 2014 Accepted: 24 March 2014

Published: 31 March 2014

\section{References}

1. Dash AP, Valecha N, Anvikar AR, Kumar A: Malaria in India: challenges and opportunities. J Biosci 2008, 33:583-592.

2. Baird JK, Basri H, Purnomo, Bangs MJ, Subianto B, Patchen LC, Hoffman SL: Resistance to chloroquine by Plasmodium vivax in Irian Jaya, Indonesia. Am J Trop Med Hyg 1991, 44:547-552.

3. Schwartz IK, Lackritz EM, Patchen LC: Chloroquine-resistant Plasmodium vivax from Indonesia. N Engl J Med 1991, 324:927.

4. Rieckmann $\mathrm{KH}$, Davis DR, Hutton DC: Plasmodium vivax resistance to chloroquine? Lancet 1989, 2:1183-1184

5. Alecrim MG, Alecrim W, Macedo V: Plasmodium vivax resistance to chloroquine (R2) and mefloquine (R3) in Brazilian Amazon region. Rev Soc Bras Med Trop 1999, 32:67-68

6. Phillips EJ, Keystone JS, Kain KC: Failure of combined chloroquine and high-dose primaquine therapy for Plasmodium vivax malaria acquired in Guyana, South America. Clin Infect Dis 1996, 23:1171-1173.

7. Soto J, Toledo J, Gutierrez P, Luzz M, Llinas N, Cedeno N, Dunne M, Berman $\mathrm{J}$ : Plasmodium vivax clinically resistant to chloroquine in Colombia. Am J Trop Med Hyg 2001, 65:90-93.

8. Smithuis F, Shahmanesh M, Kyaw MK, Savran O, Lwin S, White NJ: Comparison of chloroquine, sulfadoxine/pyrimethamine, mefloquine and mefloquine-artesunate for the treatment of falciparum malaria in Kachin State, North Myanmar. Trop Med Int Health 2004, 9:1184-1190.

9. Dua VK, Kar PK, Sharma VP: Chloroquine resistant Plasmodium vivax malaria in India. Trop Med Int Health 1996, 1:816-819.

10. Garg M, Gopinathan N, Bodhe P, Kshirsagar NA: Vivax malaria resistant to chloroquine: case reports from Bombay. Trans R Soc Trop Med Hyg 1995, 89:656-657.

11. Kshirsagar NA, Gogtay NJ, Rajgor D, Dalvi SS, Wakde M: An unusual case of multidrug-resistant Plasmodium vivax malaria in Mumbai (Bombay), India. Ann Trop Med Parasitol 2000, 94:189-190.

12. Nandy A, Addy M, Maji AK, Bandyopadhyay AK: Monitoring the chloroquine sensitivity of Plasmodium vivax from Calcutta and Orissa, India. Ann Trop Med Parasitol 2003, 97:215-220.

13. Singh RK: Emergence of chloroquine-resistant vivax malaria in south Bihar (India). Trans R Soc Trop Med Hyg 2000, 94:327.

14. Awasthi G, Satya Prasad GB, Das A: Pfcrt haplotypes and the evolutionary history of chloroquine-resistant Plasmodium falciparum. Mem Inst Oswaldo Cruz 2012, 107:129-134.

15. Sharma VP: Battling the malaria iceberg with chloroquine in India. Malar J 2007, 6:105.

16. Sehgal PN SM, Sharma SL, Gogai S: Resistance to chloroquine in falciparum malaria in Assam state, India. J Commun Dis 1973, 5:175-180.

17. Fidock DA, Nomura T, Talley AK, Cooper RA, Dzekunov SM, Ferdig MT, Ursos LM, Sidhu AB, Naude B, Deitsch KW, Su XZ, Wootton JC, Roepe PD, Wellems TE: Mutations in the $P$. falciparum digestive vacuole transmembrane protein PfCRT and evidence for their role in chloroquine resistance. Mol Cell 2000, 6:861-871.

18. Foote SJ, Thompson JK, Cowman AF, Kemp DJ: Amplification of the multidrug resistance gene in some chloroquine-resistant isolates of $P$. falciparum. Cell 1989, 57:921-930.

19. Babiker HA, Pringle SJ, Abdel-Muhsin A, Mackinnon M, Hunt P, Walliker D: High-level chloroquine resistance in Sudanese isolates of Plasmodium falciparum is associated with mutations in the chloroquine resistance transporter gene pfcrt and the multidrug resistance gene pfmdr1. $J$ Infect Dis 2001, 183:1535-1538.

20. Chen N, Russell B, Staley J, Kotecka B, Nasveld P, Cheng Q: Sequence polymorphisms in pfcrt are strongly associated with chloroquine resistance in Plasmodium falciparum. J Infect Dis 2001, 183:1543-1545.

21. Djimde A, Doumbo OK, Cortese JF, Kayentao K, Doumbo S, Diourte Y, Coulibaly D, Dicko A, Su XZ, Nomura T, Fidock DA, Wellems TE, Plowe CV: A molecular marker for chloroquine-resistant falciparum malaria. $N$ Engl $J$ Med 2001, 344:257-263.

22. Dorsey G, Kamya MR, Singh A, Rosenthal PJ: Polymorphisms in the Plasmodium falciparum pfcrt and pfmdr-1 genes and clinical response to chloroquine in Kampala, Uganda. J Infect Dis 2001, 183:1417-1420.

23. Mayor AG, Gomez-Olive X, Aponte JJ, Casimiro S, Mabunda S, Dgedge M, Barreto A, Alonso PL: Prevalence of the K76T mutation in the putative Plasmodium falciparum chloroquine resistance transporter (pfcrt) gene and its relation to chloroquine resistance in Mozambique. $J$ Infect Dis 2001, 183:1413-1416.

24. Nomura T, Carlton JM, Baird JK, del Portillo HA, Fryauff DJ, Rathore D, Fidock DA, Su X, Collins WE, McCutchan TF, Wootton JC, Wellems TE: Evidence for different mechanisms of chloroquine resistance in 2 plasmodium species that cause human malaria. J Infect Dis 2001, 183:1653-1661.

25. Brega S, de Monbrison F, Severini C, Udomsangpetch R, Sutanto I, Ruckert P, Peyron F, Picot S: Real-time PCR for dihydrofolate reductase gene single-nucleotide polymorphisms in Plasmodium vivax isolates. Antimicrob Agents Chemother 2004, 48:2581-2587.

26. Barnadas C, Ratsimbasoa A, Tichit M, Bouchier C, Jahevitra M, Picot S, Menard D: Plasmodium vivax resistance to chloroquine in Madagascar: clinical efficacy and polymorphisms in pvmdr1 and pvcrt-o genes. Antimicrob Agents Chemother 2008, 52:4233-4240.

27. Brega $S$, Meslin B, de Monbrison F, Severini C, Gradoni L, Udomsangpetch $R$, Sutanto I, Peyron F, Picot S: Identification of the Plasmodium vivax mdr-like gene (pvmdr1) and analysis of single-nucleotide polymorphisms among isolates from different areas of endemicity. J Infect Dis 2005, 191:272-277.

28. Gama BE, Oliveira NK, Souza JM, Daniel-Ribeiro CT, Ferreira-da-Cruz Mde F: Characterisation of pvmdr1 and pvdhfr genes associated with chemoresistance in Brazilian Plasmodium vivax isolates. Mem Inst Oswaldo Cruz 2009, 104:1009-1011.

29. Ganguly S, Saha P, Guha SK, Das S, Bera DK, Biswas A, Kundu PK, Saha B, Ray K, Maji AK: In vivo therapeutic efficacy of chloroquine alone or in combination with primaquine in vivax malaria in Kolkata, West Bengal, India and polymorphism in pvmdr1 and pvcrt-0 genes. Antimicrob Agents Chemother 2012, 57:1246-1251.

30. Lu F, Gao Q, Chotivanich K, Xia H, Cao J, Udomsangpetch R, Cui L, Sattabongkot J: In vitro anti-malarial drug susceptibility of temperate Plasmodium vivax from central China. Am J Trop Med Hyg 2011, 85:197-201

31. Paul RE, Brockman A, Price RN, Luxemburger C, White NJ, Looareesuwan S, Nosten F, Day KP: Genetic analysis of Plasmodium falciparum infections on the north-western border of Thailand. Trans R Soc Trop Med Hyg 1999, 93:587-593.

32. Mint Lekweiry K, Ould Mohamed Salem Boukhary A, Gaillard T, Wurtz N, Bogreau H, Hafid JE, Trape JF, Bouchiba H, Ould Ahmedou Salem MS, Pradines B, Rogier C, Basco LK, Briolant S: Molecular surveillance of drugresistant Plasmodium vivax using pvdhfr, pvdhps and pvmdr1 markers in Nouakchott, Mauritania. J Antimicrob Chemother 2012, 67:367-374.

33. Price RN, Marfurt J, Chalfein F, Kenangalem E, Piera KA, Tjitra E, Anstey NM, Russell B: In vitro activity of pyronaridine against multidrug-resistant Plasmodium falciparum and Plasmodium vivax. Antimicrob Agents Chemother 2010, 54:5146-5150.

34. Suwanarusk R, Chavchich M, Russell B, Jaidee A, Chalfein F, Barends M, Prasetyorini B, Kenangalem E, Piera KA, Lek-Uthai U, Anstey NM, Tjitra E, Nosten F, Cheng Q, Price RN: Amplification of pvmdr1 associated with multidrug-resistant Plasmodium vivax. J Infect Dis 2008, 198:1558-1564. 
35. Suwanarusk R, Russell B, Chavchich M, Chalfein F, Kenangalem E, Kosaisavee V, Prasetyorini B, Piera KA, Barends M, Brockman A, Lek-Uthai U, Anstey NM, Tjitra E, Nosten F, Cheng Q, Price RN: Chloroquine resistant Plasmodium vivax: in vitro characterisation and association with molecular polymorphisms. PLoS One 2007, 2:e1089.

36. Chehuan YF, Costa MR, Costa JS, Alecrim MG, Nogueira F, Silveira H, Brasil LW, Melo GC, Monteiro WM, Lacerda MV: In vitro chloroquine resistance for Plasmodium vivax isolates from the Western Brazilian Amazon. Malar J 2013, 12:226.

37. Lu F, Lim CS, Nam DH, Kim K, Lin K, Kim TS, Lee HW, Chen JH, Wang Y, Sattabongkot J, Han ET: Genetic polymorphism in pvmdr1 and pvcrt-o genes in relation to in vitro drug susceptibility of Plasmodium vivax isolates from malaria-endemic countries. Acta Trop 2011, 117:69-75.

38. Mallick PK, Joshi H, Valecha N, Sharma SK, Eapen A, Bhatt RM, Srivastava HC, Sutton PL, Dash AP, Bhasin VK: Mutant pfcrt "SVMNT" haplotype and wild type pfmdr1 "N86" are endemic in Plasmodium vivax dominated areas of India under high chloroquine exposure. Malar J 2012, 11:16.

39. Schneider KA, Kim Y: Genetic hitchhiking under heterogeneous spatial selection pressures. PLoS One 2013, 8:e61742.

40. Schneider KA, Kim Y: Approximations for the hitchhiking effect caused by the evolution of antimalarial-drug resistance. J Math Biol 2011, 62:789-832.

41. Schneider KA, Kim Y: An analytical model for genetic hitchhiking in the evolution of antimalarial drug resistance. Theor Popul Biol 2010, 78:93-108.

42. Karunaweera N, Wanasekara D, Chandrasekharan V, Mendis K, Carter R: Plasmodium vivax: paroxysm-associated lipids mediate leukocyte aggregation. Malar J 2007, 6:62.

43. Sriprawat K, Kaewpongsri S, Suwanarusk R, Leimanis ML, Lek-Uthai U, Phyo AP, Snounou G, Russell B, Renia L, Nosten F: Effective and cheap removal of leukocytes and platelets from Plasmodium vivax infected blood. Malar J 2009, 8:115.

44. Russell B, Chalfein F, Prasetyorini B, Kenangalem E, Piera K, Suwanarusk R, Brockman A, Prayoga P, Sugiarto P, Cheng Q, Tjitra E, Anstey NM, Price RN: Determinants of in vitro drug susceptibility testing of Plasmodium vivax. Antimicrob Agents Chemother 2008, 52:1040-1045.

45. Russell BM, Udomsangpetch $\mathrm{R}$, Rieckmann $\mathrm{KH}$, Kotecka BM, Coleman RE, Sattabongkot J: Simple in vitro assay for determining the sensitivity of Plasmodium vivax isolates from fresh human blood to antimalarials in areas where P. vivax is endemic. Antimicrob Agents Chemother 2003, 47:170-173.

46. Rubio JM, Post RJ, van Leeuwen WM, Henry MC, Lindergard G, Hommel M: Alternative polymerase chain reaction method to identify Plasmodium species in human blood samples: the semi-nested multiplex malaria PCR (SnM-PCR). Trans R Soc Trop Med Hyg 2002, 96(Suppl 1):S199-204.

47. Gouy M, Guindon S, Gascuel O: SeaView version 4: a multiplatform graphical user interface for sequence alignment and phylogenetic tree building. Mol Biol Evol 2010, 27:221-224.

48. Sutton PL: A call to arms: on refining Plasmodium vivax microsatellite marker panels for comparing global diversity. Malar J 2013, 12:447.

49. Anderson TJ, Haubold B, Williams JT, Estrada-Franco JG, Richardson L, Mollinedo R, Bockarie M, Mokili J, Mharakurwa S, French N, Whitworth J, Velez ID, Brockman AH, Nosten F, Ferreira MU, Day KP: Microsatellite markers reveal a spectrum of population structures in the malaria parasite Plasmodium falciparum. Mol Biol Evol 2000, 17:1467-1482.

50. Excoffier L, Slatkin M: Maximum-likelihood estimation of molecular haplotype frequencies in a diploid population. Mol Biol Evol 1995, 12:921-927.

51. Rice JA: Mathematical statistics and data analysis. 2nd edition. Belmont, CA Duxburry Press; 1995

52. Baird JK, Hoffman SL: Primaquine therapy for malaria. Clin Infect Dis 2004 39:1336-1345

53. Kitchen SF: Malariology. London: W B Saunders; 1939

54. Adak T, Sharma VP, Orlov VS: Studies on the Plasmodium vivax relapse pattern in Delhi, India. Am J Trop Med Hyg 1998, 59:175-179.

55. Adak T, Valecha N, Sharma VP: Plasmodium vivax polymorphism in a clinical drug trial. Clin Diagn Lab Immunol 2001, 8:891-894.

56. Gogtay NJ, Desai S, Kadam VS, Kamtekar KD, Dalvi SS, Kshirsagar NA: Relapse pattern of Plasmodium vivax in Mumbai: a study of 283 cases of vivax malaria. J Assoc Physicians India 2000, 48:1085-1086.

57. Rajgor DD, Gogtay NJ, Kadam VS, Kamtekar KD, Dalvi SS, Chogle AR, Aigal U, Bichile LS, Kain KC, Kshirsagar NA: Efficacy of a 14-day primaquine regimen in preventing relapses in patients with Plasmodium vivax malaria in Mumbai, India. Trans R Soc Trop Med Hyg 2003, 97:438-440.

58. White NJ: Determinants of relapse periodicity in Plasmodium vivax malaria. Malar J 2011, 10:297.

59. WHO: World malaria report 2011. Geneva: World Health Organization. http://www. who.int/malaria/world malaria report_2011/9789241564403_eng.pdf.

60. Das A, Anvikar AR, Cator L, Dhiman RC, Eapen A, Mishra N, Nagpal BN, Nanda N, Raghavendra K, Read AF, Sharma SK, Singh OP, Singh V, Sinnis P, Srivastava HC, Sullivan SA, Sutton PL, Thomas MB, Carlton JM, Valecha N: Malaria in India: the center for the study of complex malaria in India. Acta Trop 2012, 121:267-273.

61. Druilhe P, Brasseur P, Blanc C, Makler M: Improved assessment of Plasmodium vivax response to antimalarial drugs by a colorimetric double-site plasmodium lactate dehydrogenase antigen capture enzyme-linked immunosorbent assay. Antimicrob Agents Chemother 2007, 51:2112-2116

62. Imwong M, Pukrittayakamee $\mathrm{S}$, Pongtavornpinyo W, Nakeesathit $\mathrm{S}$, Nair $\mathrm{S}$, Newton P, Nosten F, Anderson TJ, Dondorp A, Day NP, White NJ: Gene amplification of the multidrug resistance 1 gene of Plasmodium vivax isolates from Thailand, Laos, and Myanmar. Antimicrob Agents Chemother 2008, 52:2657-2659.

63. Ranjitkar S, Schousboe ML, Thomsen TT, Adhikari M, Kapel CM, Bygbjerg IC, Alifrangis M: Prevalence of molecular markers of anti-malarial drug resistance in Plasmodium vivax and Plasmodium falciparum in two districts of Nepal. Malar J 2011, 10:75

64. Orjuela-Sanchez P, de Santana Filho FS, Machado-Lima A, Chehuan YF, Costa MR, Alecrim M, del Portillo HA: Analysis of single-nucleotide polymorphisms in the crt-o and mdr1 genes of Plasmodium vivax among chloroquine-resistant isolates from the Brazilian Amazon region. Antimicrob Agents Chemother 2009, 53:3561-3564.

65. Picot S, Brega S, Gerome P, Velut G, de Monbrison F, Cheminel V, Peyron F: Absence of nucleotide polymorphism in a Plasmodium vivax multidrug resistance gene after failure of mefloquine prophylaxis in French Guyana. Trans R Soc Trop Med Hyg 2005, 99:234-237.

66. Sa JM, Nomura T, Neves J, Baird JK, Wellems TE, del Portillo HA: Plasmodium vivax: allele variants of the $\operatorname{mdr} 1$ gene do not associate with chloroquine resistance among isolates from Brazil, Papua, and monkey-adapted strains. Exp Parasitol 2005, 109:256-259.

doi:10.1186/1475-2875-13-129

Cite this article as: Shalini et al:: Chloroquine efficacy studies confirm drug susceptibility of Plasmodium vivax in Chennai, India. Malaria Journal 2014 13:129.

\section{Submit your next manuscript to BioMed Central and take full advantage of:}

- Convenient online submission

- Thorough peer review

- No space constraints or color figure charges

- Immediate publication on acceptance

- Inclusion in PubMed, CAS, Scopus and Google Scholar

- Research which is freely available for redistribution 